\title{
THE PHYSICAL MODELLING OF HIGH SPEED BROACHING OF THE HEAT-RESISTANT STEELS FOR STUDIES SURFACE LAYER QUALITY
}

\author{
Olha Dvirna \\ Gdynia Maritime University, Faculty of Marine Engineering \\ Morska Street 81-87, 81-225 Gdynia, Poland \\ tel.: $+48585586434,+48585586331$ \\ e-mail:o.dvirna@wm.umg.edu.pl
}

\begin{abstract}
The main idea of the work is to create a physical model of high speed broaching heat-resistant materials is used to study the parameters of the surface layer quality. Modelling is a method of mediated cognition, in which the object under study is in some correspondence with the model, and the object-model is capable in some way or another to replace the original at some stages of the cognitive process. Physical modelling is primarily distinguished by the fact that studies are conducted on models with physical similarity, i.e. preserving completely (or at least partially) the nature of the phenomena. The work of the broach can be likened to the work of a number of planning cutter displaced relative to each other by a small amount, which is called lifting (feed per tooth). Therefore, for experimental work, a planning cutter of a special geometric was designed and manufactured - a physical model of a broach, in which geometric, mechanical and dynamic similarity is realized. The article also presents an experimental justification for the use of the created physical model in the study of the surface quality parameters of the, tab grooves of turbine and compressors disks made of heat-resistant materials.
\end{abstract}

Keywords: physical modelling, high-speed broaching, surface quality, tab grooves, heat-resistant steel

\section{Introduction}

At present, the technological bases for the formation of the main parameters of the quality of the processed surface of new heat-resistant materials under conditions of increased cutting speeds remain not studied [1-5]. Therefore, to study the quality parameters of the surface layer in the range of increased speeds, a physical model of the broaching was created.

By definition, a model is a natural or artificial object that is in accordance with the object under study or one of its sides. Modelling is a method of mediated cognition, in which the object under study is in some correspondence with the model, and the model object is able in some way to replace the original at some stages of the cognitive process [6]. Physical modelling is primarily distinguished by the fact that studies are conducted on installations that have physical similarity, i.e. preserving completely (or at least partially) the nature of the phenomena. The similarity of phenomena means that the data on the occurrence of processes obtained in the study of a single phenomenon can be extended to all phenomena similar to this one. With physical similarity, the fields of the corresponding physical parameters of the two systems are similar in space and time [7].

\section{The physical modelling of the broaching}

When the physical model of broaching was created then investigations of the surface quality parameters in high speeds condition to make possible. To substantiate the physical similarity of the planning and broaching process, a comparative analysis of both processes was carried out. Broaching is the process of deforming the material under conditions of non-free cutting. The main 
movement (Dr) - forward rectilinear, makes the broach. The kinematic scheme of broaching is realized in two versions (Fig. 1).

a)

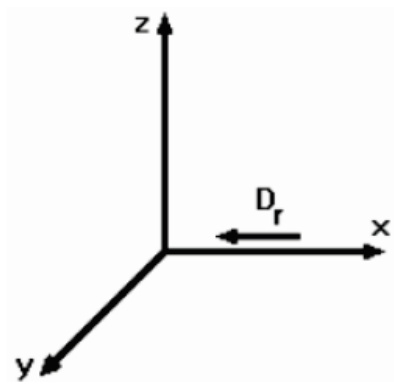

b)

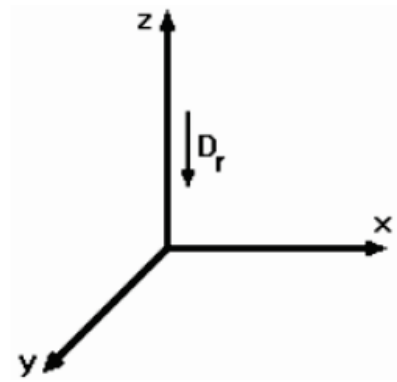

Fig. 1. The kinematic scheme of broaching: a) a schematic diagram of the operation of a horizontal broaching machine, b) a diagram of a vertical broaching machine

In planning the surfaces profile section with a rectilinear edge are machined. They are based on the simplest kinematic cutting scheme, providing for the action in the process of cutting only one main movement - straight directional speed. In these studies, the cutting is carried out on a crossplaner machine, the main motion on which the cutter makes, and the workpiece, fixed on the machine table, makes the movement of feeds (Fig. 2).

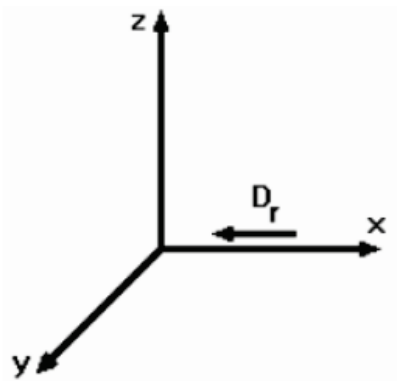

Fig. 2. The kinematic planning scheme

Since all the studies described in this work were carried out on a horizontal broaching machine and the location of the cutting edge relative to the direction of the main cutting movement in both cases is rectangular, the kinematic similarity of the broaching and planning processes is provided. The difference in the planning in a certain simplification of the conditions the formation of chips takes place the process of free cutting. The deformed state of the layer being cut off is in this case flat, i.e. deformation takes place in planes parallel to each other, and all elementary volumes of the layer being cut off can move freely in parallel directions. The use of free cutting in experimental studies makes it possible to eliminate the complicated deformation of the machined layer.

The work of the broach can be likened to the work of a number of planning tools displaced relative to each other by a small amount, which is called feeding to the tooth. It determines the thickness of the metal layer removed by each tooth (Fig. 3) [8].

For experimental, a special planning tool was designed and manufactured (Ukrainian Patent No. 65776). The material and geometry are identical to the geometry and material of the broach teeth. The working element of the planning was cut by an electric-spark method from the broach and fixated on the tool (Fig. 4).

Basing was carried out on the polished plane-parallel surfaces of the cutting element and the front surface of the cutter head. Therefore, it is safe to speak about the geometric similarity of the two considered processes. The dynamic similarity is realized by the similarity of systems of forces applied in the process of cutting to the front and rear surfaces of the planer blade and the pulling tooth from the material of the workpiece $[2,3,9]$. Consequently, the mechanics of the planning and broaching process are physically similar. 

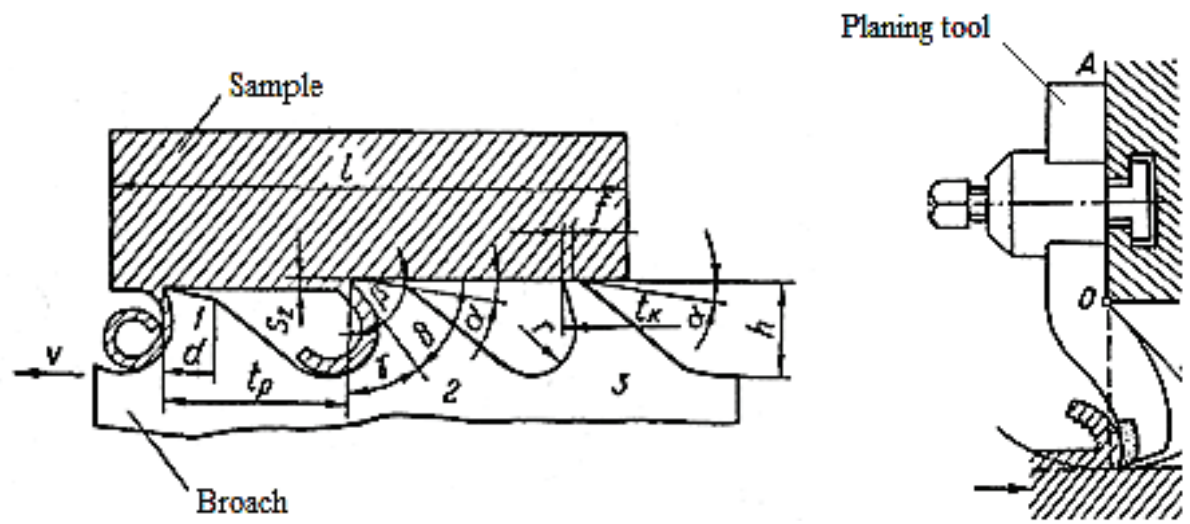

Fig. 3. Elements and geometry of teeth: a) broaching tool, b) planning tool
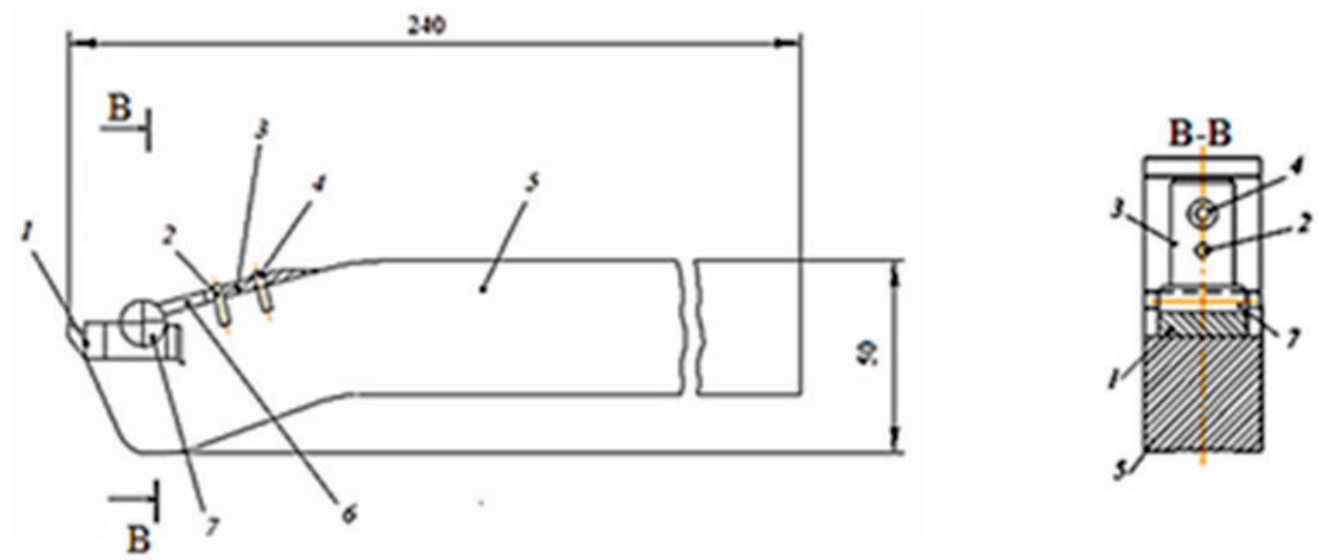

a)
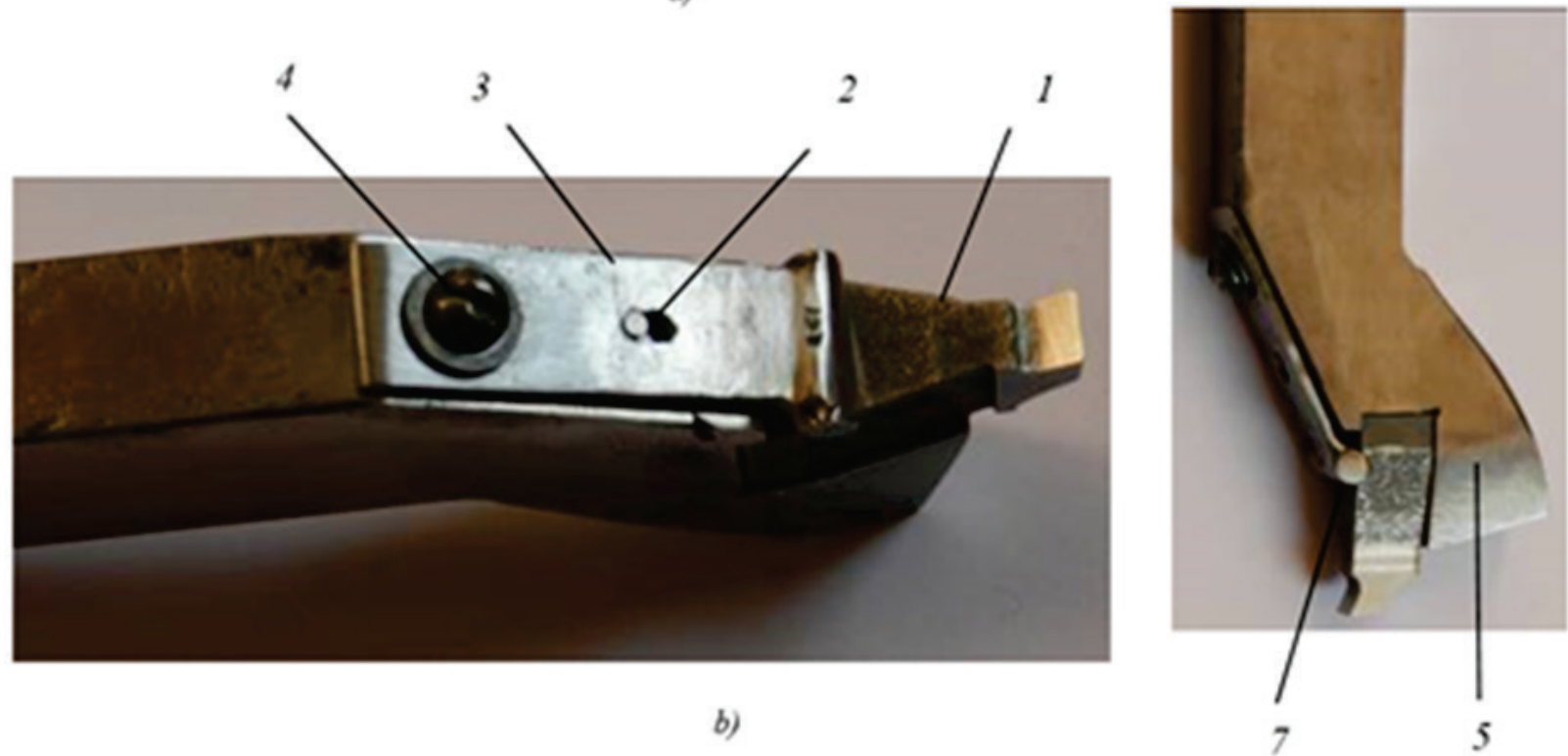

b)

7

5

Fig. 4. Special planning tool: a) drawing, b) photo): 1 -cutting element, 2 - pin, 3 -fixing plate, 4 - screw 5 -holder, 6-stop, 7 - the cylinder

\section{Experimental approbation of the physical model}

For practical confirmation of the expediency of applying the planning process in studies of the quality parameters of the machined surface in the range of medium and high cutting speeds, a series of additional experiments were carried out. On the planning and broaching machines were processed the same samples with identical cutting conditions. Planning was carried out on a 7A33 
cross-planer. Broaching of experimental samples was carried out on a horizontal-broaching machine model 7B57; the maximum cutting speed is $5 \mathrm{~m} / \mathrm{min}$ (according to the passport $12 \mathrm{~m} / \mathrm{min}$ ). Based on this limitation, cutting speeds acceptable for both types of cutting (planning and broaching) were chosen. In this experiment, the task was set: to give a conclusion on the expediency of replacing the broaching process with planning based on the degree of convergence of the results of studying the influence of technological factors of the planning process and broaching on the quality of the processed surface. To solve the problem, a full factorial experiment was carried out; and the convergence of the results obtained during planning and broaching was evaluated. The number of all combinations of levels' factors or the number of experiments 16 when broaching was the same when planning. The order of the experiments was chosen on the basis of the principles of minimizing the time to re-install the part and the tool, readjust the equipment. The initial data and the experiment plan are shown in Tab. 1 and 2.

Tab. 1. Values of factors and levels of their variation

\begin{tabular}{|l|c|c|c|c|}
\hline \multicolumn{1}{|c|}{ Characteristic } & $\begin{array}{c}V \\
{[\mathrm{~m} / \mathrm{min}]}\end{array}$ & $\begin{array}{c}S \\
{[\mathrm{~mm} / \text { tooth }]}\end{array}$ & $\begin{array}{c}\gamma \\
{\left[{ }^{\circ}\right]}\end{array}$ & HRC \\
\hline Low Level & 2.3 & 0.05 & 20 & 32 \\
\hline Up level & 3.0 & 0.1 & 27 & 39 \\
\hline
\end{tabular}

Tab. 2. Experiment Planning Matrix $2^{4}$

\begin{tabular}{|c|c|c|c|c|c|c|c|c|}
\hline $\begin{array}{c}\text { No. of } \\
\text { experiences }\end{array}$ & $X 1$ & $X 2$ & $X 3$ & $X 4$ & $\begin{array}{c}V \\
{[\mathrm{~m} / \mathrm{min}]}\end{array}$ & $\begin{array}{c}S \\
{[\mathrm{~mm} / \text { tooth }]}\end{array}$ & $\begin{array}{c}\gamma \\
{\left[{ }^{\circ}\right]}\end{array}$ & HRC \\
\hline 1 & -1 & -1 & -1 & -1 & 2.3 & 0.05 & 20 & 32 \\
\hline 2 & +1 & -1 & -1 & -1 & 3.0 & 0.05 & 20 & 32 \\
\hline 3 & -1 & +1 & -1 & -1 & 2.3 & 0.1 & 20 & 32 \\
\hline 4 & +1 & +1 & -1 & -1 & 3.0 & 0.1 & 20 & 32 \\
\hline 5 & -1 & -1 & +1 & -1 & 2.3 & 0.05 & 27 & 32 \\
\hline 6 & +1 & -1 & +1 & -1 & 3.0 & 0.05 & 27 & 32 \\
\hline 7 & -1 & +1 & +1 & -1 & 2.3 & 0.1 & 27 & 32 \\
\hline 8 & +1 & +1 & +1 & -1 & 3.0 & 0.1 & 27 & 32 \\
\hline 9 & -1 & -1 & -1 & +1 & 2.3 & 0.05 & 20 & 40 \\
\hline 10 & +1 & -1 & -1 & +1 & 3.0 & 0.05 & 20 & 40 \\
\hline 11 & -1 & +1 & -1 & +1 & 2.3 & 0.1 & 20 & 40 \\
\hline 12 & +1 & +1 & -1 & +1 & 3.0 & 0.1 & 20 & 40 \\
\hline 13 & -1 & -1 & +1 & +1 & 2.3 & 0.05 & 27 & 40 \\
\hline 14 & +1 & -1 & +1 & +1 & 3.0 & 0.05 & 27 & 40 \\
\hline 15 & -1 & +1 & +1 & +1 & 2.3 & 0.1 & 27 & 40 \\
\hline 16 & +1 & +1 & +1 & +1 & 3.0 & 0.1 & 27 & 40 \\
\hline
\end{tabular}

The quality of the treated surface, in this experiment, was determined by the level of its roughness. The measurements on the studied images were performed at three points, outside the effect of the edge effect on the profilometer 296; the results were averaged (Tab. 3 and 4).

For a visual assessment of the convergence of the experimental results (roughness of the processed surface), photographs were taken of the real surface of all the slots with a 20 -fold increase in the Neophot reflected light photomicroscope. The results are shown in Tab. 5. 
Tab. 3. The results of planning

\begin{tabular}{|c|c|c|c|c|c|c|c|c|c|}
\hline No. & $\begin{array}{c}V \\
{[\mathrm{~m} / \mathrm{min}]}\end{array}$ & $\begin{array}{c}S \\
{[\mathrm{~mm} / \text { tooth }]}\end{array}$ & $\begin{array}{c}\gamma \\
{\left[{ }^{\circ}\right]}\end{array}$ & $H R C$ & $R a_{1}$ & $R a_{\mathrm{a} 1}$ & $R a_{2}$ & $R a_{\mathrm{a} 2}$ & $R a_{\mathrm{a}}$ \\
\hline 1 & 2.3 & 0.05 & 20 & 32 & $3.11 ; 3.08 ; 3.68$ & 3.53 & $2.61 ; 2.87 ; 2.95$ & 2.81 & 3.17 \\
\hline 2 & 3.0 & 0.05 & 20 & 32 & $2.09 ; 2.18 ; 2.02$ & 2.10 & $2.05 ; 2.17 ; 2.08$ & 2.10 & 2.10 \\
\hline 3 & 2.3 & 0.1 & 20 & 32 & $2.96 ; 3.60 ; 2 ; 79$ & 3.12 & $2.80 ; 2.53 ; 2.92$ & 2.75 & 2.94 \\
\hline 4 & 3.0 & 0.1 & 20 & 32 & $2.50 ; 2.44 ; 2.12$ & 2.35 & $2.55 ; 2.57 ; 2.80$ & 2.64 & 2.50 \\
\hline 5 & 2.3 & 0.05 & 27 & 32 & $3.12 ; 2.80 ; 2.89$ & 2.93 & $2.44 ; 2.27 ; 2.46$ & 2.39 & 2.66 \\
\hline 6 & 3.0 & 0.05 & 27 & 32 & $2.19 ; 2.20 ; 2.70$ & 2.36 & $1.85 ; 1.56 ; 2.23$ & 1.88 & 2.12 \\
\hline 7 & 2.3 & 0.1 & 27 & 32 & $2.73 ; 3.26 ; 2.44$ & 2.81 & $2.37 ; 2.50 ; 2.55$ & 2.47 & 2.64 \\
\hline 8 & 3.0 & 0.1 & 27 & 32 & $1.67 ; 1.79 ; 2.39$ & 1.95 & $1.54 ; 1.54 ; 2.09$ & 1.72 & 1.84 \\
\hline 9 & 2.3 & 0.05 & 20 & 40 & $1.62 ; 1.26 ; 1.71$ & 1.53 & $1.88 ; 2.07 ; 2.04$ & 2.00 & 1.76 \\
\hline 10 & 3.0 & 0.05 & 20 & 40 & $2.25 ; 2.13 ; 1.44$ & 1.94 & $1.19 ; 1.89 ; 1.24$ & 1.44 & 1.69 \\
\hline 11 & 2.3 & 0.1 & 20 & 40 & $1.70 ; 1.23 ; 1.45$ & 1.46 & $1.87 ; 2.00 ; 1.98$ & 1.95 & 1.70 \\
\hline 12 & 3.0 & 0.1 & 20 & 40 & $1.98 ; 1.35 ; 2.00$ & 1.78 & $1.34 ; 1.94 ; 1.71$ & 1.66 & 1.72 \\
\hline 13 & 2.3 & 0.05 & 27 & 40 & $1.57 ; 1.57 ; 2.00$ & 1.71 & $1.49 ; 1.51 ; 1.77$ & 1.59 & 1.65 \\
\hline 14 & 3.0 & 0.05 & 27 & 40 & $1.18 ; 0.86 ; 0.78$ & 0.94 & $1.38 ; 1.41 ; 1.76$ & 1.52 & 1.23 \\
\hline 15 & 2.3 & 0.1 & 27 & 40 & $1.48 ; 1.62 ; 1.90$ & 1.67 & $1.29 ; 1.50 ; 1.85$ & 1.55 & 1.61 \\
\hline 16 & 3.0 & 0.1 & 27 & 40 & $1.39 ; 1.45 ; 1.50$ & 1.45 & $1.20 ; 1.63 ; 1.90$ & 1.58 & 1.52 \\
\hline
\end{tabular}

Tab. 4. The results of broaching

\begin{tabular}{|c|c|c|c|c|c|c|c|c|c|}
\hline No. & $\begin{array}{c}V \\
{[\mathrm{~m} / \mathrm{min}]}\end{array}$ & $\begin{array}{c}S \\
{[\mathrm{~mm} / \text { tooth }]}\end{array}$ & $\begin{array}{c}\gamma \\
{\left[{ }^{\circ}\right]}\end{array}$ & $H R C$ & $R a_{1}$ & $R a_{\mathrm{a} 1}$ & $R a_{2}$ & $R a_{\mathrm{a} 2}$ & $R a_{\mathrm{a}}$ \\
\hline 1 & 2.3 & 0.05 & 20 & 32 & $2.56 ; 2.43 ; 2.00$ & 2.33 & $2.34 ; 2.58 ; 2.60$ & 2.50 & 2.42 \\
\hline 2 & 3.0 & 0.05 & 20 & 32 & $2.09 ; 2.29 ; 2.04$ & 2.14 & $1.98 ; 2.01 ; 1.75$ & 1.91 & 2.03 \\
\hline 3 & 2.3 & 0.1 & 20 & 32 & $2.58 ; 2.15 ; 1.26$ & 2.00 & $2.07 ; 2.19 ; 2.00$ & 2.09 & 2.05 \\
\hline 4 & 3.0 & 0.1 & 20 & 32 & $2.26 ; 2.18 ; 1.68$ & 2.04 & $1.95 ; 2.04 ; 1.73$ & 1.90 & 1.97 \\
\hline 5 & 2.3 & 0.05 & 27 & 32 & $2.01 ; 2.15 ; 1.89$ & 2.02 & $1.68 ; 1.77 ; 1.85$ & 1.77 & 1.90 \\
\hline 6 & 3.0 & 0.05 & 27 & 32 & $2.18 ; 1.94 ; 2.00$ & 2.04 & $1.49 ; 1.67 ; 1.34$ & 1.49 & 1.77 \\
\hline 7 & 2.3 & 0.1 & 27 & 32 & $1.72 ; 2.04 ; 1.57$ & 1.78 & $1.65 ; 2.09 ; 2.09$ & 1.94 & 1.86 \\
\hline 8 & 3.0 & 0.1 & 27 & 32 & $1.55 ; 1.84 ; 1.40$ & 1.60 & $1.64 ; 1.33 ; 1.79$ & 1.59 & 1.60 \\
\hline 9 & 2.3 & 0.05 & 20 & 40 & $1.57 ; 2.04 ; 1.65$ & 1.75 & $1.26 ; 1.48 ; 1.72$ & 1.49 & 1.60 \\
\hline 10 & 3.0 & 0.05 & 20 & 40 & $1.42 ; 1.87 ; 1.07$ & 1.45 & $1.37 ; 1.31 ; 1.49$ & 1.39 & 1.42 \\
\hline 11 & 2.3 & 0.1 & 20 & 40 & $1.73 ; 1.45 ; 1.44$ & 1.54 & $1.31 ; 1.87 ; 1.32$ & 1.50 & 1.52 \\
\hline 12 & 3.0 & 0.1 & 20 & 40 & $1.18 ; 1.24 ; 0.98$ & 1.13 & $0.81 ; 1.22 ; 1.33$ & 1.12 & 1.13 \\
\hline 13 & 2.3 & 0.05 & 27 & 40 & $0.97 ; 1.24 ; 0.88$ & 1.03 & $0.98 ; 1.18 ; 0.96$ & 1.04 & 1.04 \\
\hline 14 & 3.0 & 0.05 & 27 & 40 & $1.02 ; 0.76 ; 0.89$ & 0.88 & $0.94 ; 0.93 ; 1.31$ & 1.06 & 0.97 \\
\hline 15 & 2.3 & 0.1 & 27 & 40 & $0.95 ; 0.96 ; 0.90$ & 0.94 & $1.09 ; 0.87 ; 0.94$ & 0.97 & 0.96 \\
\hline 16 & 3.0 & 0.1 & 27 & 40 & $0.97 ; 0.75 ; 0.87$ & 0.86 & $0.98 ; 0.79 ; 0.99$ & 0.92 & 0.89 \\
\hline
\end{tabular}


Tab. 5. Comparative analysis of the conditions for broaching and planning of steel EP517

\begin{tabular}{|l|c|c|}
\hline \multirow{2}{*}{\multicolumn{1}{|c|}{ Compare parameter }} & \multicolumn{2}{|c|}{ Comparison } \\
\cline { 2 - 3 } Kinematics and geometry & Horizontal-broaching machine 7657 & Cross-planning machine 7A33 \\
\cline { 2 - 3 } $\begin{array}{l}\text { The main movement }\left(\mathrm{D}_{\mathrm{r}}\right)- \\
\text { - forward rectilinear }\end{array}$ & & \\
\hline
\end{tabular}

\section{Conclusions}

From the analysis of the parameter values and photographs of the roughness of the surfaces formed during planning and broaching follows:

1) The level of roughness the broached surface is lower than planed surface on all similar samples. This fact is explained by the technological system on a broaching machine is more rigid. On a planer, the tool experiences certain vibrations.

2) The average discrepancy between the experimental values does not exceed $23.5 \%$.

3) In both cases, the same patterns are observed (roughness decreases with increasing sample hardness and, in some cases, cutting speed, using a tool with a front angle of $27^{\circ}$ provides a smoother surface).

4) The texture and surface defects are identical.

5) The nature of the hardening of the surface layer and the distribution of residual stresses in it are similar. 


\section{References}

[1] Dvirna, O., Analysis of applied technologies of surface treatment locks grape compressor and turbine, Scientific Letters of Rzeszow University of Technology, Mechanics, pp. 433-440, Rzeszow 2018.

[2] Dvirnaya, O. Z., Shumilov, A. P., Research of the quality of the machined groove surface in samples of steel EP517, Actual problems of mechanical engineering: Materials of the International Conference, NUK, pp. 137-138, Mykolaiv 2011.

[3] Dvirnaya, O. Z., Shumilov, A. P., Modern methods of processing the locking grooves in the GTE, Actual problems of engineering: Materials of the International Conference, NUK, pp. 112-115, Mykolaiv 2011.

[4] Vedmedovsky, V. A., Problems of improving the quality of the surface layer during highspeed broaching. Increasing the efficiency of broaching, Riga Polytechnic Institute, pp. 164-174, Riga 1986.

[5] Zemlyansky, V. A., Lukshin, B. V., Processing of high-strength materials with tools with self-rotating cutters, Technique, Kiev 1980.

[6] Katsev, P. G., Processing by broaching, Handbook, Mashinostroenie, Moscow 1986.

[7] Margulis, M. M., Tverskoy, D. K., Vakurova, V. A. et. al., Broaching tool: calculation, design, manufacturing technology, Metallurgy, Chelyabinsk 1992.

[8] Wulf, A. M., Metal cutting, Mechanical Engineering, Leningrad 1973.

[9] Granovsky, G. I., Granovsky, V. G., Cutting of metals, A textbook for the machine industry and priborostr. Specialist. Universities, Higher School, Moscow 1985.

Manuscript received 05 July 2019; approved for printing 22 September 2019 